\title{
KOMPOSISI BAHAN AJAR KONSEP ANALISIS REAL "SUPREMUM DAN INFIMUM" LAPISAN DALAM BUMI MELALUI PEMBELAJARAN ETNOMATEMATIKA SUNDA
}

\author{
Supriadi \\ Universitas Pendidikan Indonesia \\ Kampus Serang Jl. Ciracas Serang Banten \\ Email: supriadi.upiserang@upi.edu
}

\begin{abstract}
Teaching materials have been prepared using the concept of Ethnomatematics Sunda who believe that mathematics is a product of a culture. Supremum and Infrimum is part of mathematics that we can serve to connect the values of philosophy of Sundanese culture as a giver of value in understanding the concept of real analysis. Learning will be more memorable for studying mathematics at once understand the cultural aspects.
\end{abstract}

Key words: Ethnomathematics Sunda, Supremum and Infrimun

\section{PENDAHULUAN}

Pembelajaran matematika memerlukan penyajian yakng menarik agar siswa yang mempelajarinya akan tertarik.Contohnya mata kuliah Analisis Real yang dipandang sulit dipahami oleh siswa. Matematika masih merupakan salah satu bidang studi yang sulit dan anggapan bahwa matematika tidak disenangi atau bahkan paling dibenci, masih saja melekat pada kebanyakan siswa yang mempelajarinya (Ruseffendi,1984).Namun sebagai guru/dosen kita bisa diam saja melihat permasalahan di atas. Hasil belajar sangat ditentukan sekali oleh keberhasilan siswa dalam belajar. Namun keberhasilan tersebut tidak hanya ditentukan oleh faktor siswa saja, tetapi juga oleh faktor di luar siswa, antara lain adalah faktor guru. Dalam hal yang sama Ruseffendi (1991:8) mengemukakan bahwa keberhasilan siswa dalam mengajar dipengaruhi oleh beberapa faktor. Faktor dari dalam diri siswa itu meliputi kecerdasan anak, kesiapan anak, kenyamanan belajar dan minat anak belajar, adapun faktor dari luar diri siswa adalah metode penyajian materi pelajaran, pribadi dan sikap guru, suasana pengajaran, kompetensi guru dan kondisi masyarakat luar.

Salah satu faktor terpenting dalam keberhasilan siswa dalam belajar adalah metode penyajian materi pelajaran. Apakah materi yang disajikan membuat siswa tertarik, termotivasi, kemudian timbul perasaan pada diri siswa untuk menyenangi materi, dan adanya kebutuhan terhadap materi tersebut? Ataukah justru cara penyajian materi hanya akan membuat siswa jenuh terhadap matematika?

Salah satu penyajian materi analisis real yaitu dengan menggunakan pembelajaran etnomatematika Sunda, sehingga pembelajaran analisis real menjadi menarik karena dapat memperoleh nilai dari sebuah budaya.

\section{A. Pembelajaran Etnomatematika Sunda dalam materi Supremun dan infrimun}

Konsep etnomatematika Sunda menurut Supriadi (2014, hlm. 231) adalah semua kegiatan ide seseorang dengan didasari oleh pandangan budaya Sunda (nilai-nilai budaya Sunda) yang dikembangkan melalui proses berpikir matematika, dengan memandang bahwa matematika adalah produk budaya. 


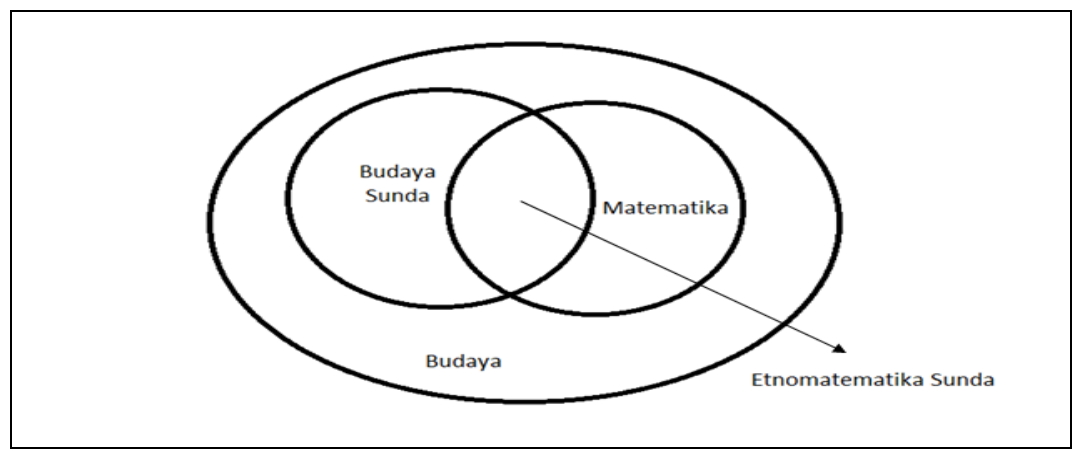

Konsep Etnomatematika Sunda (Supriadi, 2014)

\section{Nilai-Nilai Filosofi Pembelajaran Etnomatematika Sunda}

Nilai budaya Sunda merupakan tuntunan hidup orang Sunda yang berhubungan dengan Tuhan, pribadinya sesama manusia, terhadap alam, dan terhadap waktu (Suryalaga, dalam Abdullah, 2013, hlm. 16). Nilai budaya Sunda sebagai perilaku manusia Sunda dalam menghadapi perubahan cara menghadapi masalah, serta sikap terhadap pendapat dan konflik (Mariana dan Paskrina, 2006, hlm. 65). Nilai budaya Sunda adalah sebagai konsep yang dimiliki orang Sunda dalam menghadapi masalah kehidupan dan penghidupannya di dunia ini.

Kemudian definisi Sunda menurut beberapa ahli: 24):

Suryalaga (dalam Abdullah, 2013, hlm.

a. Bahasa Sansekerta

Arti kata Sunda adalah: bercahaya, terang benderang, salah satu Dewa Wisnu yang mempunyai 1000 nama, seorang satri wanara dalam epos Ramayana, putih dan nama sebuah gunung pada masa silam yang berada di sebuah utara Kota Bandung. Dikenal dengan nama gunung Sunda yang terlihat putih karena diselimuti oleh abu Vulkanik.

b. Bahasa Kawi

Arti kata Sunda adalah: air, tumpukan,pangkat,dan waspada.

c. Bahasa Jawa
Arti kata Sunda adalah: tersusun, merangkap,menyatu,angka daua dalam perhitungan candrasangkala suryasangkala,naik, dan terbang.

d. Bahasa Sunda

Arti kata Sunda adalah:

Sa-unda mengandung arti tempat menyimpan padi atau lumbung.

Sonda mengandung arti bagus, indah, unggul,senang,puas hati,setuju dan sesuai dengan keinginan.

Sundara artinya laki-laki tampan, dan nama Dewa Kamajaya.

Sunda, dalam kata sundari artinya perempua yang cantik rupawan.

Sunda, artinya indah dan molek.

e. Bahasa Kawi-Perancis

Sunda artinya sangat indah dan subur

f. Bahasa Arab

Sunda tersusun atas huruf Arab yang berasal dari Syin-Nun-Dal, penanaman suatu wilayah yang bergunung-gunung, seperti tatar Sunda yang bergununggunung.

Sunda diartikan pula wilayah tempat orang kembali. Dalam kajian geografi R.W Van Bemmelen (Suryalaga dalam Abdullah, 2013, hlm. 25) menyatakan:

1) Sunda yaitu penamaan wilayah barat laut dari India Timur yang dikelilingi sistem Gunung Sunda sepanjang 7.000 $\mathrm{km}$, mulai dari kepulauan Filipina, 
Formusa, sampai lembah Brahmaputra di India.

2) Sunda dalam Sunda Besar adalah himpunan pulau-pulau besar di Wilayah Indonesia, yaitu: Sumatra, Jawa, Madura, dan Kalimantan.

3) Sunda dalam Sunda kecil meliputi Bali, Nusa Tenggara dan Timor.

Berdasarkan makna dari nilai budaya Sunda, Suryalaga, Garna (Abdullah, 2013, hlm. 27) dan (Suryani, 2011, hlm. 119) mengelompokkan nilai budaya Sunda terdiri atas hubungan manusia dengan Tuhan, hubungan manusia sebagai pribadinya, hubungan manusia dengan sesama manusia, dan hubungan manusia dengan alam. Nilai budaya yang digunakan dalam penelitian ini adalah nilai budaya Sunda hubungan manusia dengan alam.

Satriawinara (Abdullah, 2013, hlm. 36) menyatakan orang Sunda beranggapan bahwa lingkungan alam memberikan manfaat yang maksimal kepada manusia apabila dijaga kelestariannya, dirawat serta dipelihara dengan baik dan digunakan hanya secukupnya saja. Kalau alam digunakan berlebihan apabila kalau tidak dirawat dan tidak dijaga kelestariannya, maka akan timbul malapetaka dan kesengsaraan. Orang Sunda dianjurkan agar siger tengah atau siniger tengah yaitu tidak kekurangan tetapi tidak berlebihan. Sama sekali bukan untuk kemewahan melainkan hanya untuk memenuhi kebutuhan sehari-hari. Dengan demikian, tidak menguras atau memeras alam secara berlebihan, sehingga terjaga kelestariannya.

Imel (Abdullah, 2013, hlm. 36) menyatakan nilai budaya Sunda yang berhubungan manusia dengan alam dapat tercermin dalam ungkapan

a. Gunung teu meunang di lebur, sagara teu meunang di ruksak, buyut teu meunang dirempak artinya gunung tidak boleh dihancurkan, laut tidak boleh dirusak dan sejarah tidak boleh dilupakan harus sesuai dengan alam.

b. Tatangkalan di leuweung teh kudu di pupusti artinya pepohonan di hutan harus dihormati. c. Leuweung ruksak, cai beak, manusa balangsak artinya hutan dan sumber air harus dijaga kalau tidak maka manusia akan sengsara.

\section{B. Konsep analisis real "supremum dan infimum"}

\section{Supremum dan Infimum}

Berikut ini diperkenalkan konsep tentang batas atas dan batas bawah dari suatu

himpunan bilangan real.

Definisi 1 Diberikan subset tak kosong $S \subset \Re$.

(a) Himpunan $S$ dikatakan terbatas ke atas (bounded above) jika terdapat

suatu bilangan $u \in \mathfrak{R}$ sedemikian hingga $s \leq u$ untuk semua $s \in S$. Setiap

bilangan $u$ seperti ini disebut dengan batas atas (upper bound) dari $S$.

(b) Himpunan $S$ dikatakan terbatas ke bawah (bounded below) jika terdapat

suatu bilangan $w \in \mathfrak{R}$ sedemikian hingga $w \leq s$ untuk semua $s \in S$. Setiap

bilangan $w$ seperti ini disebut dengan batas bawah (lower bound) dari $S$.

(c) Suatu himpunan dikatakan terbatas (bounded) jika terbatas ke atas dan

terbatas ke bawah. Jika tidak, maka dikatakan tidak terbatas (unbounded).

Contoh

1. himpunan $S:=\{x \in \mathfrak{R}: x<7\}$ ini terbatas ke atas, sebab bilangan 7 dan sebarang bilangan lebih dari 7 merupakan batas atas dari $S$. Himpunan ini tidak mempunyai batas bawah, jadi himpunan ini tidak terbatas ke bawah. Jadi, $S$ merupakan himpunan yang tidak terbatas.

2. himpunan $S:=\{x \in \mathfrak{R}: x>3\}$ ini terbatas ke bawah, sebab bilangan 3 dan sebarang bilangan bilangan kurang dari 3 merupakan batas bawah dari $S$. Himpunan ini tidak mempunyai batas atas,jadi himpunan ini tidak terbatas ke atas. Jadi , $S$ merupakan himpunan yang tidak terbatas.

3. himpunan $S:=\{x \in \mathfrak{R}: 3<x<7\}$ ini terbatas, sebab himpunan $S$ terbatas atas di bilangan 7 dan terbatas bawah di bilangan 3 .

Definisi 2. Diberikan $S$ subset tak kosong $\mathfrak{R}$ 
(a) Jika $S$ terbatas ke atas, maka suatu bilangan $u$ disebut supremum (batas

atas terkecil) dari $S$ jika memenuhi kondisi berikut:

(1) $u$ merupakan batas atas $S$, dan

(2) jika $v$ adalah sebarang batas atas $S$, maka $u$ $\leq v$.

Ditulis $u=\sup S$.

(b) Jika $S$ terbatas ke bawah, maka suatu bilangan $u$ disebut infimum (batas

bawah terbesar) dari $\mathrm{S}$ jika memenuhi kondisi berikut:

(1) $w$ merupakan batas bawah $S$, dan

(2) jika $t$ adalah sebarang batas bawah $S$, maka $t$ $\leq w$.

Ditulis $w=\inf S$.

Mudah untuk dilihat bahwa jika diberikan suatu himpunan $S$ subset dari $\mathfrak{R}$ maka hanya terdapat satu supremum, atau supremumnya tunggal. Juga dapat ditunjukkan bahwa jika $u$ ' adalah sebarang batas atas dari suatu himpunan tak kosong $S$, maka sup $S \leq u^{\prime}$, sebab sup $S$ merupakan batas atas terkecil dari $S$. Suatu subset tak kosong $S \subset \mathfrak{R}$ mempunyai empat kemungkinan, yaitu

(i) mempunyai supremum dan infimum,

(ii) hanya mempunyai supremum,

(iii) hanya mempunyai infimum,

(iv) tidak mempunyai infimum dan supremum.

Setiap bilangan real $a \in \mathfrak{R}$ merupakan batas atas dan sekaligus juga merupakan

batas bawah himpunan kosong $\varnothing$. Jadi, himpunan $\varnothing$ tidak mempunyai supremum dan infimum.

Lemma 1. Suatu bilangan u merupakan supremum dari subset tak kosong $S \subset \mathfrak{R}$

jika dan hanya jika u memenuhi kondisi berikut:

(1) $s \leq$ u untuk semua $s \in S$,

(2) jika $v<u$, maka terdapat $s^{\prime} \in S$ sedemikian hingga $x<s^{\prime}$.

Lemma 2. Diberikan subset tak kosong $S \subset \mathfrak{R}$, (a) $u=\sup S$ jika dan hanya jika untuk setiap $\varepsilon>0$ terdapat $s_{1} \in S$

sedemikian hingga $u_{1}-\varepsilon<s$. (b) $w=\inf S$ jika dan hanya jika untuk setiap $\varepsilon>0$ terdapat $s_{2} \in S$

sedemikian hingga $u_{2}-\varepsilon<s$.

Bukti.

(a) Diketahui $u=\sup S$ dan diberikan $\varepsilon>0$. Karena $u-\varepsilon<u$, maka $u-\varepsilon$

bukan merupakan batas atas $S$. Oleh karena itu, terdapat $s_{1} \in S$ yang lebih besar

dari $u-\varepsilon$, sehingga $u_{1}-\varepsilon<s$.

$\Leftarrow$ Diketahui $u_{1}-\varepsilon<s$. Jika $u$ merupakan batas atas $S$, dan jika memenuhi

$v<u$, maka diambil $\varepsilon:=u-v$. Maka jelas $\varepsilon>0$, dan diperoleh bahwa

$u=\sup S$.

\section{Contoh}

1. Jika suatu himpunan tak kosong $S_{1}$ mempunyai elemen sebanyak berhingga,

maka dapat dilihat bahwa $S_{1}$ mempunyai elemen terbesar, namakan $u$, dan

elemen terkecil, namakan $w$. Maka $u=\sup$

$S_{1}$ dan $w=\inf S_{1}$, dan keduanya

merupakan elemen $S_{1}$.

2. Himpunan $S_{2}:=\{x \in \mathfrak{R}: 3<x<7\}$ mempunyai batas atas 7. Akan dibuktikan bahwa 7 merupakan supremumnya. Misalkan $v<7$, maka terdapat $s^{\prime} \in S_{2}$

$$
\begin{aligned}
& s^{\prime}=\frac{v+7}{2} \\
& v<7 \\
& v<\frac{v+7}{2}<7 \\
& v<s^{\prime}
\end{aligned}
$$

(Teorema 5.7)

Karena $v$ bukan batas atas dari $S_{2}$ maka 7 adalah supremum dari $S_{2}$

Himpunan $S_{2}$ juga mempunyai bata bawah 3.Akan dibuktika bahwa 3 merupakan infimumnya.Misalkan $w>3$ maka terdapat $u^{\prime} \in S_{2}$ dengan 
$u^{\prime}=\frac{w+3}{2}$

$3<w$

$3<\frac{w+3}{2}<w$

$3<u^{\prime}<w$

$u^{\prime}<w$

Karena $w>u^{\prime}$ jadi $w$ bukan batas bawah dari $S_{2}$ maka 3 adalah batas bawah terbesar atau 3 merupakan infimum dari $S_{2}$. Karena Himpunan $S_{2}$ memiliki Supremum dan Infimum maka himpunan $S_{2}$ terbatas (bounded)

\section{Pembelajaran Etnomatematika Sunda Dalam Materi Supremum dan Infimum Pada Lapisan Dalam Bumi}
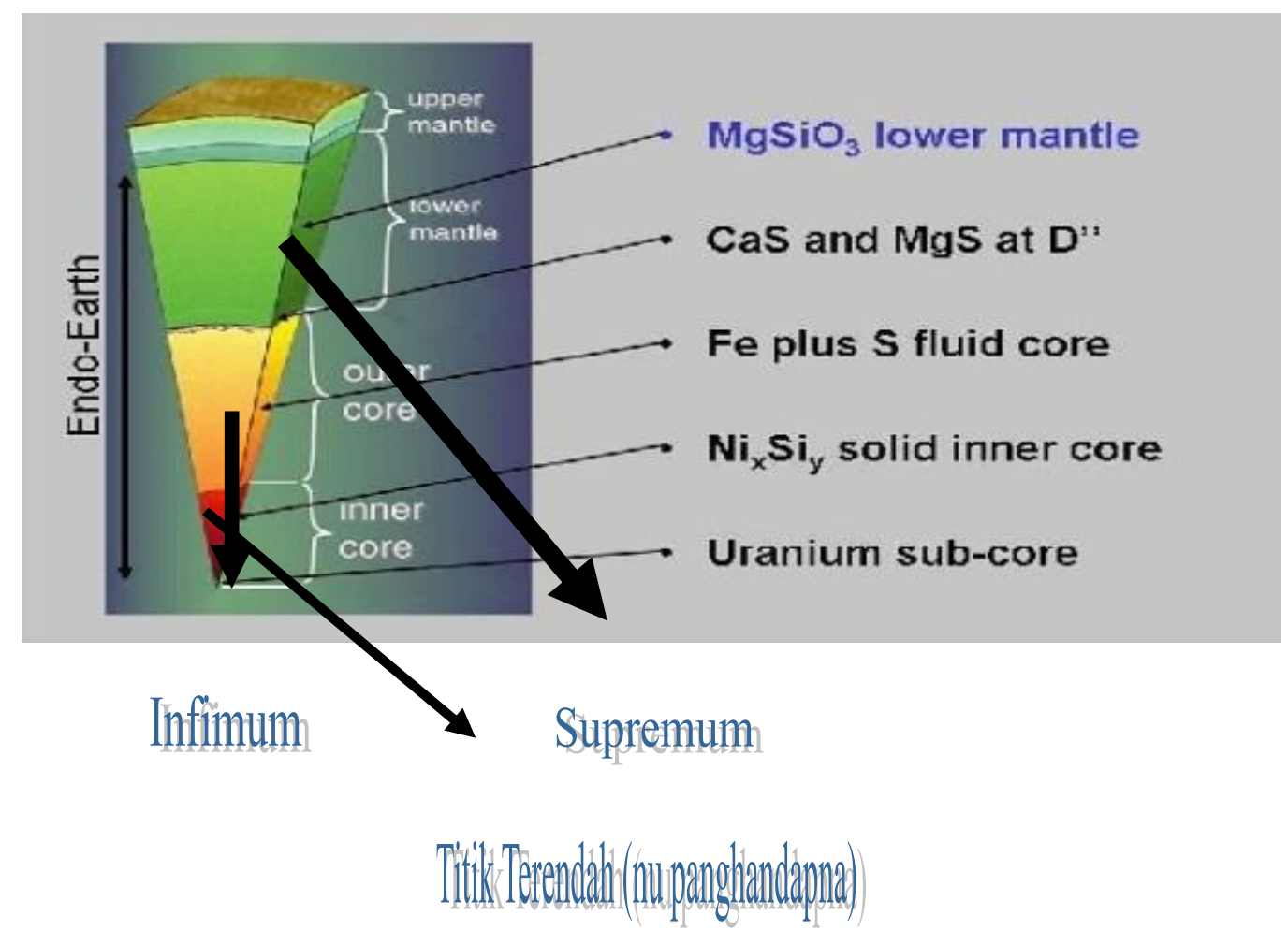

\section{Nilai Filosofi Sunda}

Gunung teu meunang di lebur, sagara teu meunang di ruksak, buyut teu meunang dirempak artinya gunung tidak boleh dihancurkan, laut tidak boleh dirusak dan sejarah tidak boleh dilupakan harus sesuai dengan alam. Bumi harus dipelihara agar tidak rusak lapisan bumi yang Lapisan dalam Bumi yang terbagi dari mantel atas (mantel luhur),mantel bawah (mantel handap),inti luar (inti anu luar) dan inti dalam (inti nu jero).

\section{Permasalahan Kontekstual}

Dalam lapisan inti luar kita dapat menentukan sebuah Supremum dan Infimum. Aplikasi pembelajaran: Bumi diperkirakan tersusun atas inti dalam bumi (inner core) yang 
terdiri dari besi nikel beku setebal 1.370 kilometer dengan suhu $4.500^{\circ} \mathrm{C}$, diselimuti pula oleh inti luar (outer core) yang bersifat cair setebal 2.100 kilometer, lalu diselimuti pula oleh mantel (lower mantle) silika setebal 2.800 kilometer membentuk $83 \%$ isi bumi, dan akhirnya sekali diselimuti oleh kerak bumi(upper mantle) setebal kurang lebih 85 kilometer.

Jika kita refleksikan ke dalan model matematika maka dapa kita tuliskan sebagai berikut:

Tabel.1

\begin{tabular}{llll}
\hline No & Lapisan & Ketebalan $(\mathrm{Km})$ & Jarak dari titik terendah dari lapisan inti dalam $(\mathrm{Km})$ \\
\hline 1 & Inti dalam & 1370 & 1370 \\
2 & Inti Luar & 2100 & $1370+2100=3470$ \\
3 & Mantel & 2800 & $1370+2100+2800=6270$ \\
4 & kerak & 85 & $1370+2100+2800+85=6355$ \\
\hline
\end{tabular}

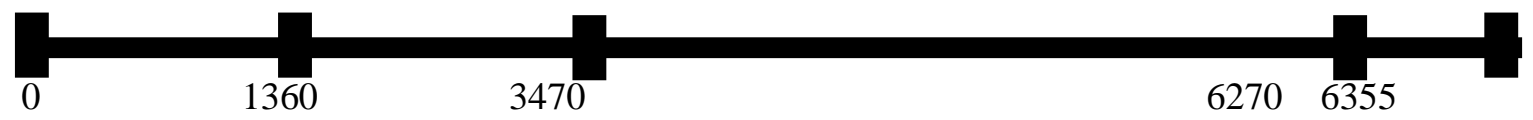

Dalam LKM di atas kita dapat menentukan supremum dan infimum

Misal Himpunan lapisan dalam bumi adalah subset dari bilangan real Dari LKM di atas kita menentukan himpunan Himpunan $S:=\{x$ $\in \mathfrak{R}: 1360<x<3470\}$

Himpunan $S$ mempunyai batas atas 3470 .

Akan dibuktikan bahwa

3470 merupakan supremumnya. Misalkan $v$ $<3470$, maka terdapat $s^{\prime} \in S$

$$
\begin{aligned}
& s^{\prime}=\frac{v+3470}{2} \\
& v<3470 \\
& v<\frac{v+3470}{2}<3470 \\
& v<s^{\prime}
\end{aligned}
$$

(Teorema 5.7)

Karena $v$ bukan batas atas dari $S$ maka 3470 adalah supremum dari $S$

Himpunan $S$ juga mempunyai batas bawah 1360.Akan dibuktikan bahwa 1360 merupakan infimumnya.Misalkan $w>1360$ maka terdapat $u^{\prime} \in S$ dengan

$$
\begin{aligned}
& u^{\prime}=\frac{w+1360}{2} \\
& 1360<w \\
& 1360<\frac{w+1360}{2}<w \\
& 1360<u^{\prime}<w \\
& u^{\prime}<w
\end{aligned}
$$

Karena $w>u$ jadi $w$ bukan batas bawah dari $S$ maka 1360 adalah batas bawah terbesar atau 1360 merupakan infimum dari $S$.Karena Himpunan $S$ memiliki Supremum dan Infimum maka himpunan $S$ terbatas (bounded)

\section{KESIMPULAN}

Pembelajaran etnomatematika Sunda dalam materi Supremum dan Infimum memberikan sebuah nilai positif bagi mahasiswa bahwa seiring perubahan zaman, nilai-nilai budaya Sunda tetap tidak berubah. Mahasiswa yang berasal dari budaya Sunda adalah mereka yang mengakui dirinya dan diakui oleh orang-orang lain sebagai orang Sunda, orang lain itu baik orang Sunda sendiri 
maupun orang-orang yang bukan Sunda (Suryani, 2011, hlm. 116), akan lebih termotivasi untuk melestarikan nilai-nilai budaya Sunda dalam pembelajaran. Bagi Mahasiswa yang tidak berasal dari budaya Sunda, dalam pembelajaran matematika akan terjadi situasi saling membantu, tukar informasi dan budaya dengan siswa asal budaya Sunda, sehingga terciptalah pelestarian budaya dalam kelas. Pembelajaran matematika pun tidak menjadi kaku hanya di sisi matematika saja, namun bisa berkolaborasi dengan bidang ilmu lain, yaitu budaya.

\section{DAFTAR KEPUSTAKAAN}

Abdullah. 2013. Penanaman Nilai Budaya Sunda Pada Anak Usia Dini di TK Negeri Pembina Cianjur. Skripsi UPI. Bandung: Tidak diterbitkan.
Zaki M. 2008. Pengantar Analisis Real I:Diktat Kuliah UGM

Ruseffendi ET. 1984. Dasar-dasar Matematika Modern untuk Guru.Bandung: Tarsito

Ruseffendi ET. 1991. Pengantar kepada Guru Membantu Mengembangkan Potensinya dalam Pengajaran Matematika untuk Meningkatkan CBSA.Bandung: Tarsito

Supriadi. 2014. Mengembangkan Kemampuan dan Disposisi Pemodelan serta Berpikir Kreatif Matematik Mahasiswa PGSD melalui Pembelajaran Kontekstual Berbasis Etnomatematika. Disertasi SPs UPI.Bandung: Tidak diterbitkan.

Suryani. 2011. Ragam Pesona Budaya Sunda. Bogor: Ghalia Indonesia.

Wikipedia bahasa Indonesia : 30 juni 2009 ,7. 16 